\title{
Chronic alcohol ingestion exacerbates skeletal muscle myopathy in HIV-1 transgenic rats
}

\author{
Caroline R Clary ${ }^{*}$ Daniel M Guidot*, Margaux A Bratina and Jeffrey S Otis
}

\begin{abstract}
Background: Separately, chronic alcohol ingestion and HIV-1 infection are associated with severe skeletal muscle derangements, including atrophy and wasting, weakness, and fatigue. One prospective cohort study reported that $41 \%$ of HIV-infected patients met the criteria for alcoholism, however; few reports exist on the co-morbid effects of these two disease processes on skeletal muscle homeostasis. Thus, we analyzed the atrophic effects of chronic alcohol ingestion in HIV-1 transgenic rats and identified alterations to several catabolic and anabolic factors.

Findings: Relative plantaris mass, total protein content, and fiber cross-sectional area were reduced in each experimental group compared to healthy, control-fed rats. Alcohol abuse further reduced plantaris fiber area in HIV-1 transgenic rats. Consistent with previous reports, gene levels of myostatin and its receptor activin IIB were not increased in HIV-1 transgenic rat muscle. However, myostatin and activin IIB were induced in healthy and HIV-1 transgenic rats fed alcohol for 12 weeks. Catabolic signaling factors such as TGF $\beta_{1}$, TNF $\alpha$, and phospho-p38/totalp38 were increased in all groups compared to controls. There was no effect on IL-6, leukemia inhibitory factor (LIF), cardiotrophin-1 (CT-1), or ciliary neurotrophic factor (CNTF) in control-fed, transgenic rats. However, the comorbidity of chronic alcohol abuse and HIV-1-related protein expression decreased expression of the two anabolic factors, CT-1 and CNTF.

Conclusions: Consistent with previous reports, alcohol abuse accentuated skeletal muscle atrophy in an animal model of HIV/AIDS. While some catabolic pathways known to drive alcoholic or HIV-1-associated myopathies were also elevated in this co-morbid model (e.g., TGF $\beta_{1}$ ), consistent expression patterns were not apparent. Thus, specific alterations to signaling mechanisms such as the induction of the myostatin/activin IIB system or reductions in growth factor signaling via CT-1- and CNTF-dependent mechanisms may play larger roles in the regulation of muscle mass in alcoholic, HIV-1 models.
\end{abstract}

\section{Introduction and hypotheses}

Multi-organ pathologies have been well-described in a host of systemic disease states. For example, chronic alcoholism and HIV/AIDS infection are each associated with liver and kidney complications, immune dysfunction, and cardio-respiratory alterations [1-5]. Unfortunately, the National Institutes of Alcohol Abuse and Alcoholism (NIAAA) confirmed that people infected with HIV-1 are more likely to abuse alcohol at some time during their lives [6,7] which would likely increase the incidence of health complications in this population. Further, these co-morbid alcoholic and HIV/AIDS pathologies may become more clinically apparent when

\footnotetext{
* Correspondence: clarycaro@gmail.com; guidot6@uga.edu
Department of Medicine, Emory University School of Medicine, 615 Michael

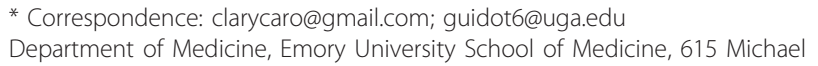
Street, Atlanta, GA 30322, USA
}

(C) 2011 Clary et al; licensee BioMed Central Ltd. This is an Open Access article distributed under the terms of the Creative Commons Attribution License (http://creativecommons.org/licenses/by/2.0), which permits unrestricted use, distribution, and reproduction in any medium, provided the original work is properly cited.

considered in parallel with increased patient survival rates due to effective antiretroviral therapy. These comorbid effects, which may include memory loss and brain damage $[8,9]$, cardiomyopathy $[10,11]$, compromised immune function [12] with increased susceptibility to opportunistic infection [13], are often severe and associated with lower perceived qualities of life compared to otherwise healthy alcoholics or HIV-1 infected patients [14]. Significant skeletal muscle derangements such as atrophy, weakness, and dysfunction are evident in both disease states [15-19]. However; few reports exist that describe the co-morbid effects of chronic alcohol ingestion and HIV-1 on skeletal muscle biology $[10,20]$.

In simian immunodeficiency virus (SIV)-infected Rhesus macaques, chronic binge-drinking during the asymptomatic phase of the disease increased viral load and skeletal 
muscle expression of inflammatory cytokines while altering nutritional intake, but did not alter rates of skeletal muscle protein synthesis or degradation [20]. However, as viral load increased and SIV infection progressed to more terminal stages (SAIDS), alcohol abuse increased expression of two muscle-specific E3 ubiquitin ligases, atrogin-1 and muscle ring finger protein-1, and drove skeletal muscle proteolysis [10]. These data clearly show that bingelike alcohol abuse exacerbates HIV-associated myopathy during the progression of the disease. Here, we extend these critical observations by Molina and colleagues by using a commercially available, infection- and replicationdeficient rat model of HIV-1 that develops many AIDSlike pathologies such as systemic muscle atrophy and weight loss, neurological abnormalities, and respiratory and immune dysfunctions [3,15,21-23],

Interestingly, AIDS-like pathologies can be replicated using in vivo and in vitro models without the influence of HIV-1 viral burden [3,23-26]. For example, evidence has implicated HIV-1-related proteins, such as gp120 and Tat, as mediators of injury even when target cells are not directly infected with HIV-1. Specifically, we have shown that atrophied skeletal muscles from HIV-1 transgenic rats have altered glutathione states and increased expression of atrogin-1 and TGF $\beta_{1}$ [15] metabolic and biochemical responses we have also documented in otherwise-healthy, alcoholic muscle [16,27].

Based on this previous work, the current study was designed to identify the catabolic effects of chronic alcohol ingestion and its influence on viral-independent mechanisms of HIV-associated myopathy. Accordingly, we fed a subset of HIV-1 transgenic rats the LieberDeCarli liquid diet plus alcohol for 12 weeks. We hypothesized that long term alcohol abuse would exacerbate skeletal muscle atrophy, drive expression of the cell cycle regulator myostatin and its receptor activin IIB, alter expression of several catabolic and anabolic IL6 family members, drive gene expression of TNF $\alpha$, and increase p38 MAPK phosphorylation [16,28-33].

\section{Results and discussion}

We have previously described plantaris atrophy in HIV-1 transgenic rats (republished in part in Figures $1 \mathrm{~A}$ and $1 \mathrm{C}$ ) and now show concomitant decreases in total protein content (Figure 1B) compared to age- and gender-matched wild type controls [15]. These
A

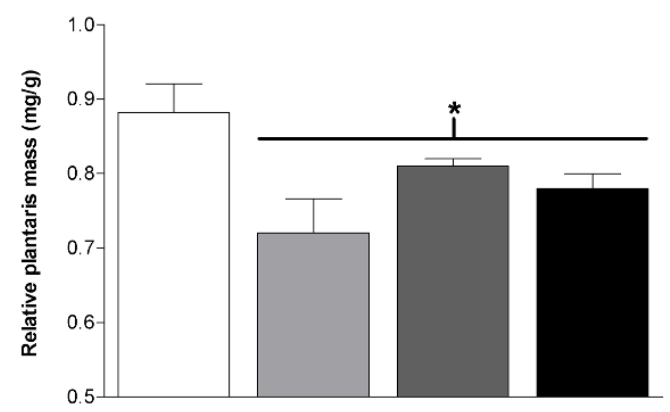

C

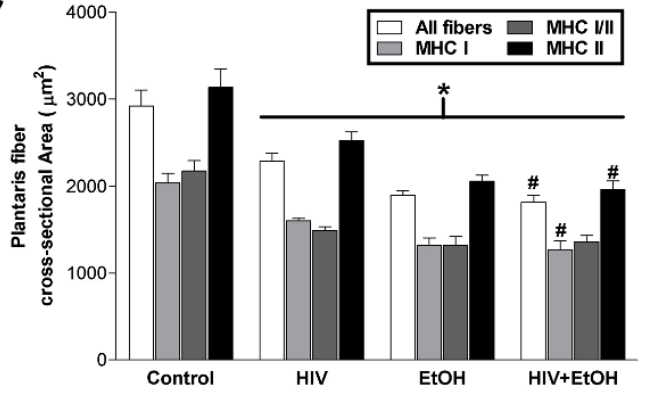

B
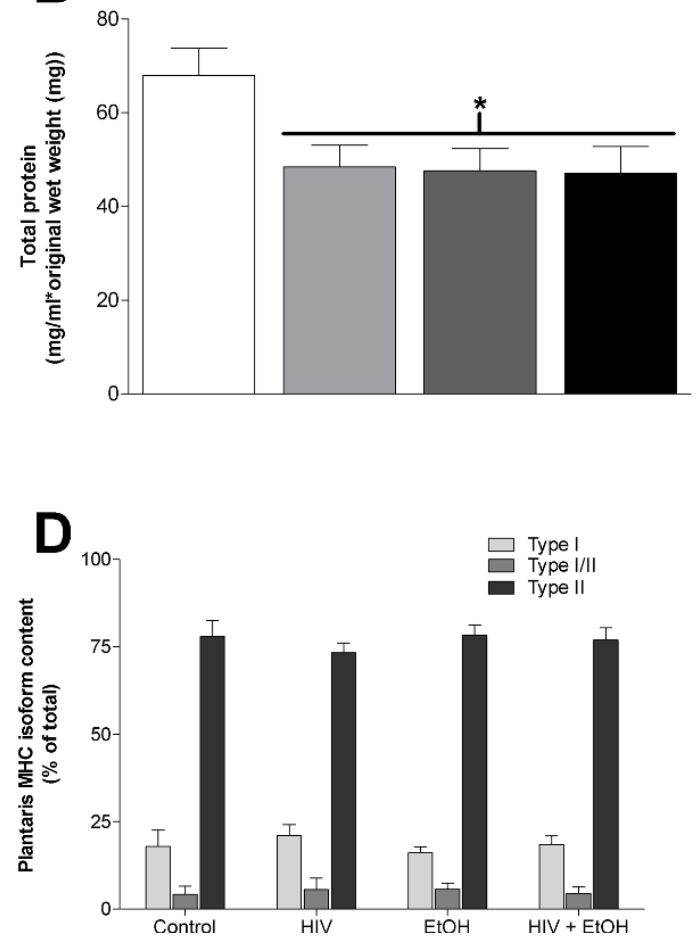

Figure 1 Chronic alcohol ingestion exacerbates plantaris fiber area in HIV-1 transgenic rats. (A) Relative plantaris mass, (B) total protein content, and (C) fiber area were reduced in each disease state. Myosin heavy chain isoform (MHC) content was unchanged in any group (D). Twelve weeks of chronic alcohol ingestion further reduced plantaris fiber area in HIV-1 transgenic rats compared to control-fed transgenic rats (C). A portion of this figure has been previously published [15]. Values are expressed as means + SEM ( $n=6-7$ rats/group). Significance was accepted at $\mathrm{p} \leq 0.05 .{ }^{*}$, compared to control-fed, otherwise-healthy rat group. \#, compared to control-fed, HIV-1 transgenic rat group. 
myopathies are readily apparent in alcoholic muscle as well (Figure 1B) and occur independent of myosin heavy chain isoform (MHC) expression (Figure 1C). Moreover, MHC isoform content was unchanged in any group (Figures 1D, 2). As expected, plantaris fiber area was further reduced in alcoholic, transgenic rats (Figure 1C). These data confirmed earlier reports from terminal stage SIV-infected (SAIDS) Rhesus macaques

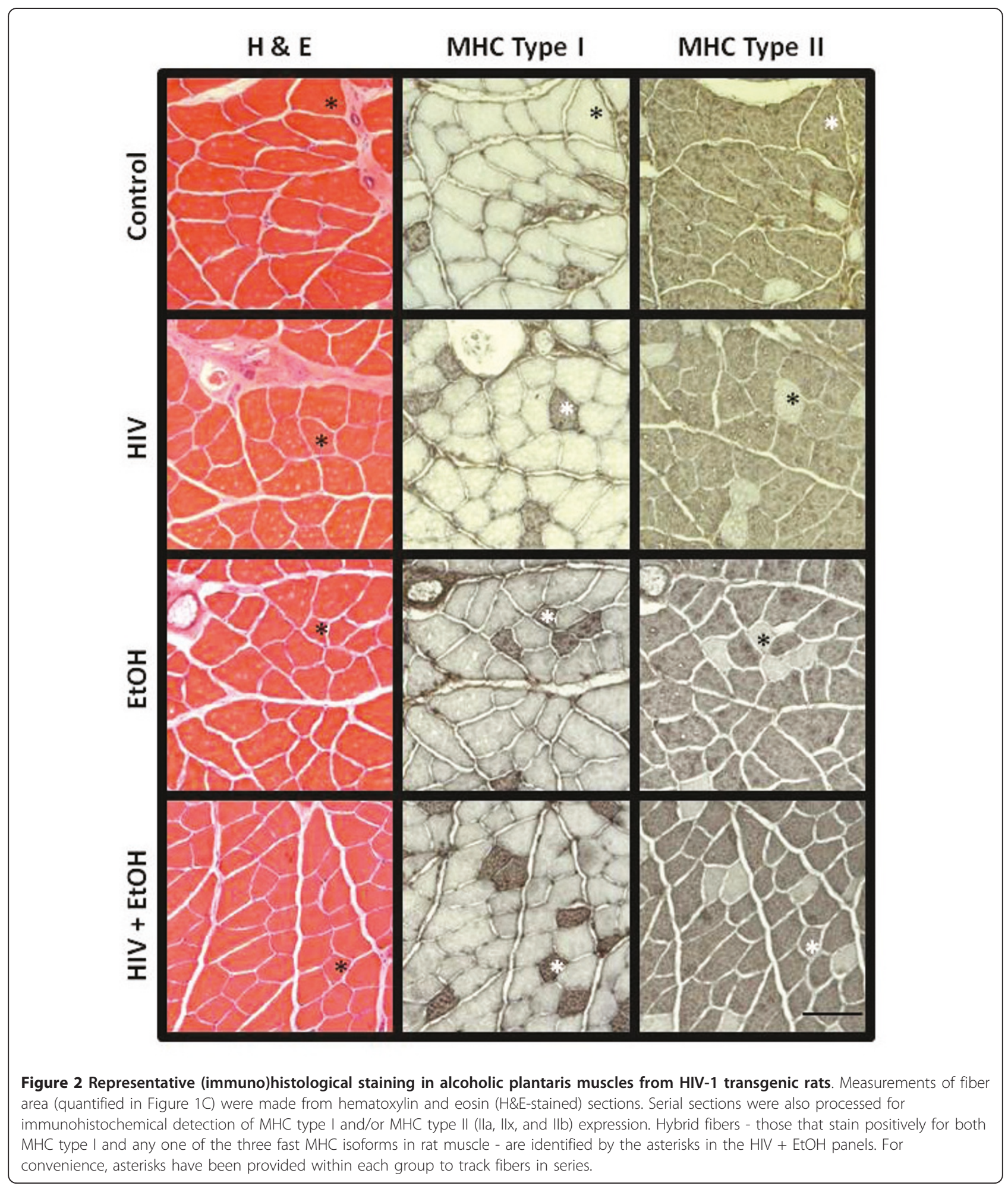


that alcohol ingestion exacerbates skeletal muscle wasting [10].

In both animal models of HIV/AIDS, the quantity and duration of alcohol abuse, in combination with the stage of disease progression, may have significant influence on the development of overt skeletal muscle atrophy. For example, in the early stages of SIV infection, binge-like alcohol ingestion in asymptomatic Rhesus macaques did not alter skeletal muscle protein synthesis nor degradation rates. However, alcohol did increase viral load and drive expression of tumor necrosis factor- $\alpha$ in skeletal muscle and may reflect the early establishment of a proatrophy program. If we had initiated our alcohol feeding paradigm during a similar, asymptomatic stage in the HIV-1 transgenic rat model (e.g., less than 5 months of age), we might have expected muscle adaptations that reflected the alcoholic, asymptomatic, SIV-infected Rhesus macaques. Our chronic alcohol feeding paradigm was started in HIV-1 transgenic rats that already displayed significant myopathies [15] and support the notion that alcohol abuse exacerbates HIV-1 associated skeletal muscle derangements [10]. Together, these data clearly confirm the importance of HIV-1 infected patients to avoid binge-like or chronic alcohol abuse or to aggressively seek treatment options to minimize the co-morbid impact of the diseases.

Myostatin, a member of the TGF $\beta$ super family and implicated in various models of skeletal muscle atrophy, likely influences skeletal muscle mass via cell cycle regulation and alterations to myogenic stem cells [34-39]. We confirm earlier reports that myostatin is upregulated in alcoholic muscle [36] (Figure 3A) and show comparable alcohol-induced increases to its receptor, activin IIB (Figure 3B). Alterations to myostatin and activin IIB were also evident in muscles from alcoholic, HIV-1 transgenic rats. However, neither gene product was elevated in control-fed, transgenic rat muscles signifying that chronic alcohol ingestion may be the significant insult that drives myostatin and activin IIB expressions, not the associated pathology of HIV-1-related proteins. Similarly, myostatin mRNA expression levels were unchanged in muscles from asymptomatic or SAIDS macaques [10] and support the notion that neither viral infection nor HIV-1-related protein expression impact myostatin signaling. However, this contention is controversial as elevated serum and intramuscular levels of myostatin appeared to play a role in AIDS-associated wasting in HIV-infected men [40]. These discrepancies in myostatin expression levels may be due in part to variations between models (i.e., murine, simian, and human), disease stage and progression, or nutritional and metabolic abnormalities. More work is required to

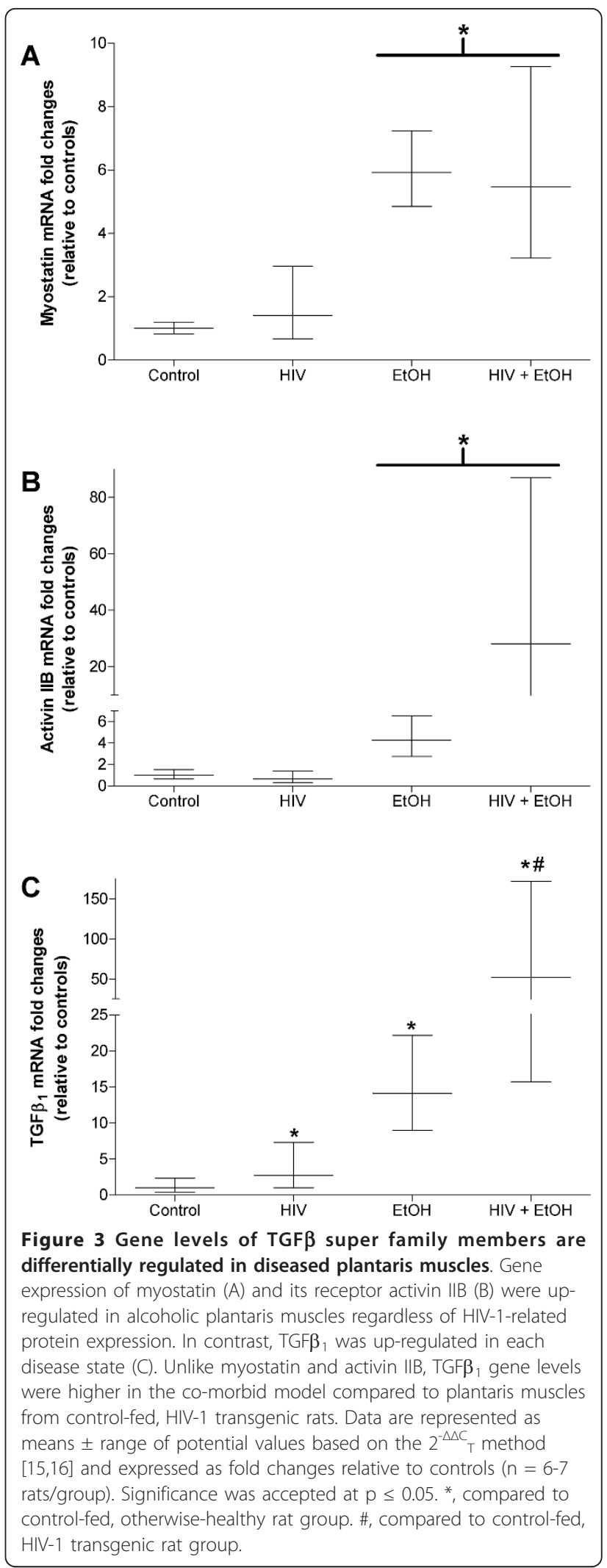


clarify the involvement of myostatin signaling in HIV-1 associated myopathies.

We also confirmed earlier reports that both alcohol abuse and HIV-1-related protein expression induce TGF $\beta_{1}$ gene expression [15,27], an effect that was further increased in the co-morbid condition (Figure $3 C)$. Predictably, the catabolic influences of chronic alcohol ingestion and HIV-1-related protein expression impact TGF $\beta$ super family members in various degrees. Although speculative, treatment options that affect a broad range of factors in skeletal muscle (e.g., anti-oxidant therapy or strength training paradigms) may prove most beneficial to maintain skeletal muscle mass.

The IL-6 family of cytokines, including IL-6, LIF, CNTF, and CT-1, regulates skeletal muscle mass $[16,28,29,41]$. We have previously shown [16] and confirmed here (Figure 4A) that long term alcohol abuse drives gene expression of IL-6, an inflammatory cytokine associated with skeletal muscle catabolism. Similarly, twelve weeks of alcohol abuse drove expression of LIF (Figure 4B), a cytokine implicated in muscle regeneration and myoblast proliferation [30,42], and may reflect an early protective response to alcohol-induced myopathy [16]. Interestingly, this alcohol-induced expression pattern was not evident in muscles alcohol-fed, HIV-1 transgenic rats (Figures 4A and $4 \mathrm{~B}$ ) suggesting that different inflammatory cytokines may play larger roles in HIV-1 myopathies. In support of this notion, we (Figure 5A) and others [20] have reported increased TNF $\alpha$ mRNA expression muscle levels of in muscles from alcoholic, HIV-1 models. Together, these data strongly suggest that the myotoxic effects of chronic alcohol ingestion may manifest via multiple signaling mechanisms that ultimately depend on the underlying health status of the abuser.
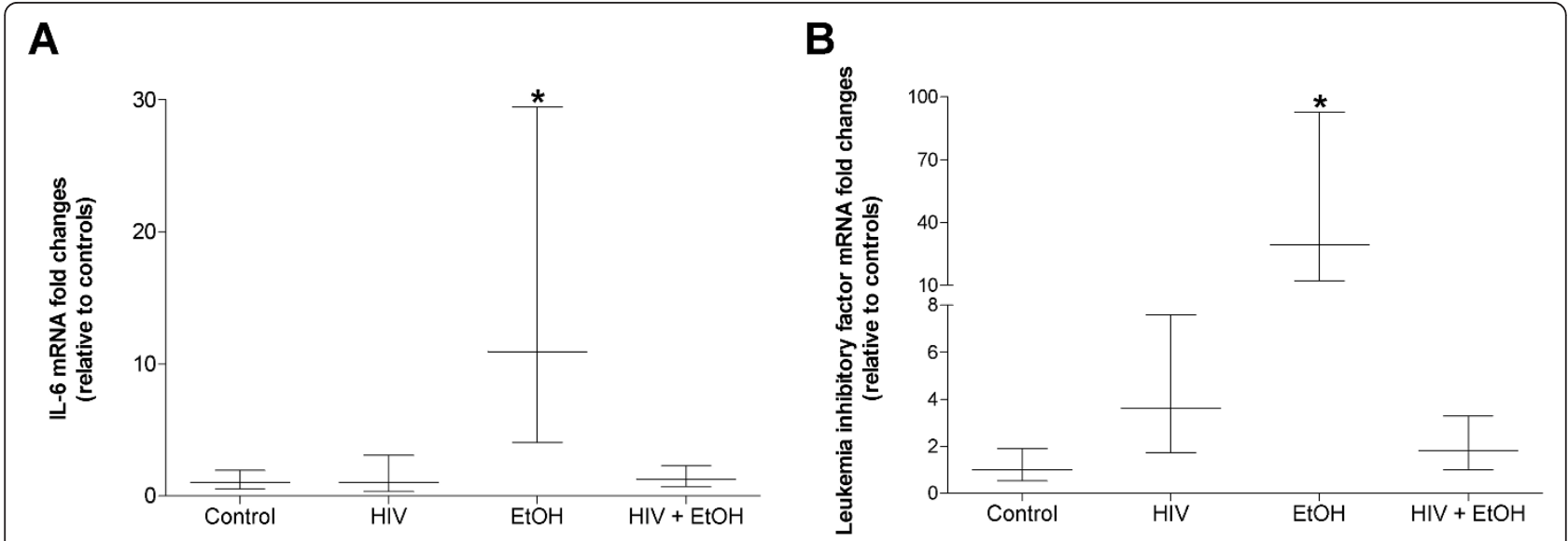

C

D
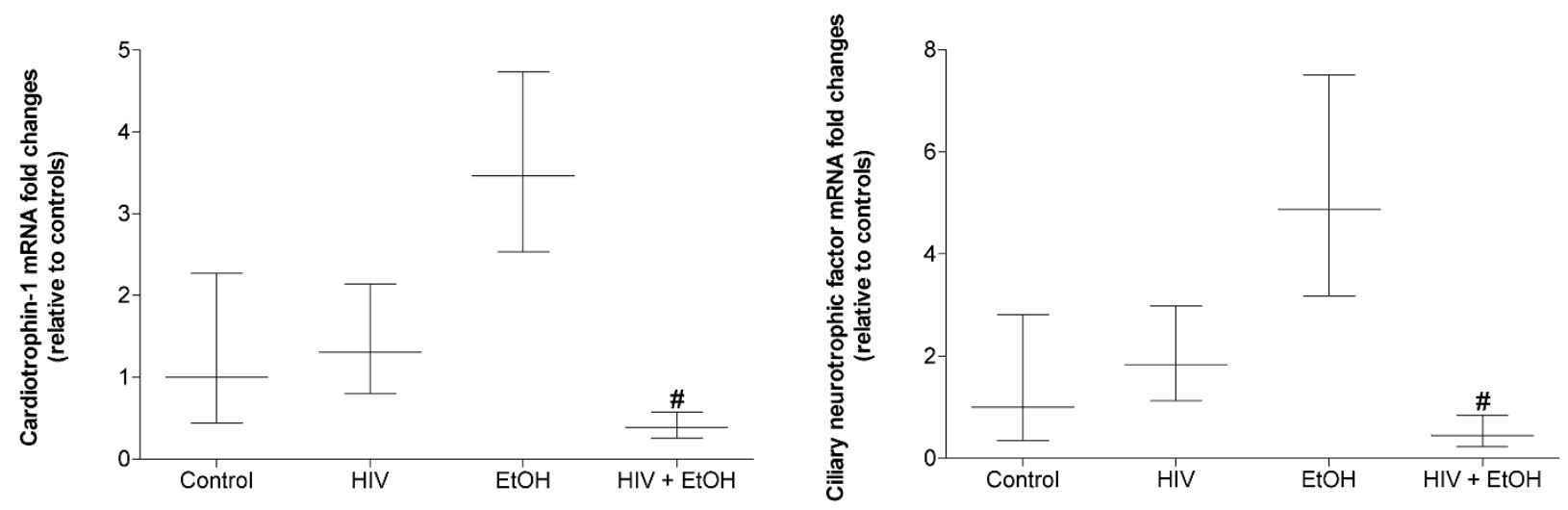

Figure 4 Gene levels of IL-6 super family members are differentially regulated in diseased plantaris muscles. As previously described [16], chronic alcohol ingestion induced expression of IL-6 (A) and LIF (B). The co-morbidity of twelve weeks of daily alcohol ingestion and HIV-1related protein expression reduced gene expression of CT-1 (C) and CNTF (D). Data are represented as means \pm range of potential values based on the $2^{-\Delta \Delta C}$ method $[15,16]$ and expressed as fold changes relative to controls ( $n=6-7$ rats/group). Significance was accepted at $p \leq 0.05 .{ }^{*}$, compared to control-fed, otherwise-healthy rats. \#, compared to control-fed, HIV-1 transgenic rats. 


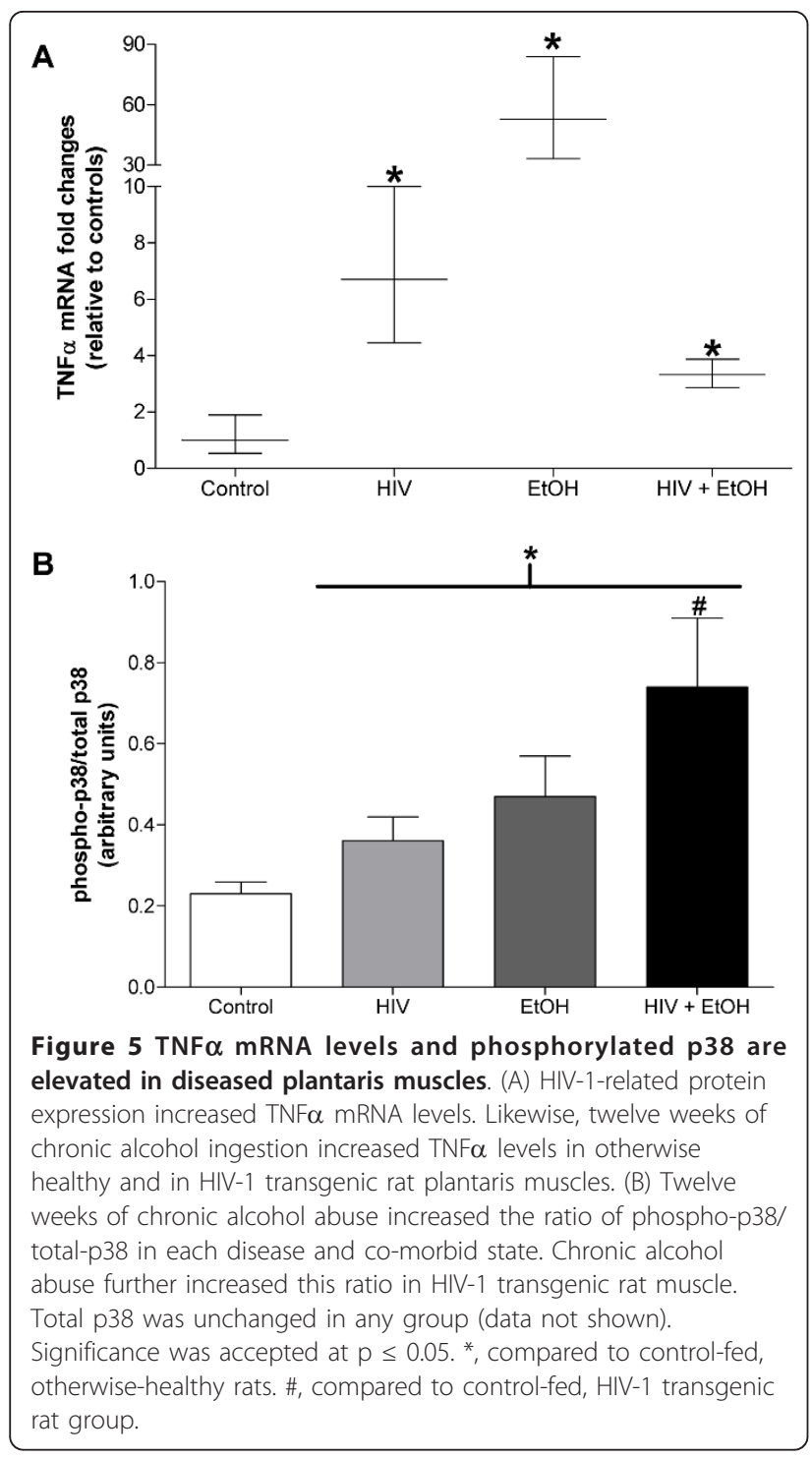

The co-morbidity of chronic alcohol ingestion and HIV-1-related protein expression reduced two anabolic IL-6 family members, CNTF and CT-1 (Figures $4 \mathrm{C}$ and 4D), which may be partially responsible for reduced plantaris mass, protein content, and fiber area (Figure 1 ). In support of this notion, suppressed levels of other anabolic growth factors such as IGF-1 have been previously described in co-morbid models [10]. Interestingly, protein synthesis rates were unchanged in alcoholic, asymptomatic or SAIDS macaques $[10,20]$ which may suggest negligible effects stemming from reduced growth factor levels. However, Molina and colleagues [10] noted that these apparent discrepancies between reduced anabolic growth factor levels and the well-established negative effects of alcohol abuse on skeletal muscle protein synthesis rates $[43,44]$ may be due in large part to variations in alcohol feeding paradigms and circulating alcohol concentrations, or in sample collection times during the post-absorptive state.

p38 MAPK is a stress-activated protein kinase implicated in skeletal muscle catabolism [45]. Interestingly, p38 MAPK phosphorylation and subsequent pathway activation may be the result of oxidative stress or TNF $\alpha$ induction - two upstream factors that we and others have shown to be elevated in alcoholic and/or HIV-1 myopathies $[15,16,20,46]$. Here, the phospho-p38/totalp38 ratio, an index of p38 activation, was elevated in each disease state (Figure 5B) suggesting that this protein kinase plays a central role in these myopathies. Moreover, TNF $\alpha$-stimulated $\mathrm{p} 38$ activation has been associated with downstream induction of atrogin-1 expression in in vitro models of muscle atrophy [33]. Atrogin-1, an E3 ubiquitin ligase, is increased in alcoholic muscle $[16,27,47]$ or muscle from HIV-1 transgenic rats [15]. Together, these data may describe a $\mathrm{TNF} \alpha / \mathrm{p} 38 /$ atrogin-1 signaling pathway in alcoholic, HIV-1 myopathies.

\section{Conclusions}

We have shown that chronic alcohol ingestion in HIV-1 transgenic rats increases skeletal muscle atrophy with concomitant losses to total protein content and relative muscle mass. These adaptations may be due in part to increased myostatin signaling, increased catabolic cytokine levels such as IL-6, TGF $\beta_{1}$, and TNF $\alpha$, altered p38 pathway activity, and decreased expression of growth factors such as CNTF and CT-1. Importantly, we have previously shown that certain catabolic factors such as atrogin- 1 and TGF $\beta_{1}$ as well as anabolic factors such as CNTF and CT-1 are redox-sensitive and can be modulated with glutathione restoration strategies in alcoholic muscle [16]. Interestingly, chronic alcohol feeding and a mouse model of AIDS infection (MAIDS) independently attenuated antioxidant defense capability in the liver, and in combination, led to an additive inhibition of glutathione [48]. Assuming an additive biochemical and pathological response to alcohol and HIV-1 exists in skeletal muscles, these data would strongly suggest that robust, anti-oxidant therapy with glutathione precursors such as procysteine, S-adenosyl methionine, or N-acetyl cysteine would impact an array of catabolic and anabolic factors and improve diseased skeletal muscle mass. These hypotheses are currently under investigation in our laboratory.

\section{Methods}

\section{Animals and diets}

Male, Fischer 344/NHsd HIV-1 transgenic rats (hemizygous NL4-3 $\Delta \mathrm{gag} / \mathrm{pol}$ ) [3] and wild type Fischer 344/ NHsd rats $(\sim 400 \mathrm{~g})$ were purchased from Harlan (Indianapolis, Indiana) and housed in pairs under a 12:12 
light-dark cycle. Animals were randomized into one of four groups ( $\mathrm{n}=6-7 /$ group): (1) wild type rats fed control diet, (2) HIV-1 transgenic rats fed control diet, (3) wild type rats fed an ethanol-containing diet, and (4) HIV-1 transgenic rats fed an ethanol-containing diet.

Rats were fed the Lieber-DeCarli liquid diet (Research Diets, New Brunswick, New Jersey) containing either alcohol or an isocaloric substitution with Maltin-Dextrin (control diet) for $12 \mathrm{wk}[16,27]$. To acclimatize the rats to the Lieber-DeCarli diet, alcohol was gradually added as $18 \%$ of total calories for $1 \mathrm{wk}$, then $27 \%$ of total calories for $1 \mathrm{wk}$, and then finally $36 \%$ of total calories for $12 \mathrm{wk}$, respectively. At the end of the $12 \mathrm{wk}$, rats were anesthetized with intraperitoneal injections of sodium pentobarbital $(50 \mathrm{mg} / \mathrm{kg})$. Muscles were removed and trimmed free of connective tissues, blotted dry, weighed, and mounted in OCT for histochemical analyses or flash frozen in liquid nitrogen for other analyses as described below. Animals were sacrificed by removal of the diaphragm muscle. All procedures were approved by Atlanta Veteran Affairs Medical Center Institutional Animal Care and Use Committee.

\section{Plantaris morphology \& myosin heavy chain (MHC) isoform expression}

Fresh plantaris muscles were embedded in OCT and immediately frozen in isopentane cooled in liquid nitrogen as previously described [15]. Serial sections from the mid-belly of the plantaris were cut at 14 or $8 \mu \mathrm{m}$ for analyses of CSA or MHC isoform determination, respectively. All incubations were performed at room temperature. For CSA determination, plantaris sections were adhered to superfrost slides, processed for hematoxylin and eosin staining, dehydrated, and mounted. For MHC isoform determination, sections were processed for immunohistochemical detection of slow or fast MHC protein expression using the ABC method (Vector Labs, Burlingame, California). Sections were rehydrated in phosphate buffered saline (PBS, pH 7.4), incubated in blocking solution for $20 \mathrm{~min}$, and then incubated in anti-slow MHC or anti-fast MHC IgG (Sigma, St. Louis, Missouri) for $90 \mathrm{~min}$. Sections were washed in PBS, incubated in biotinylated secondary antibody for $60 \mathrm{~min}$, washed again in PBS, and then incubated in an avidin-rich solution for $60 \mathrm{~min}$. After a final wash, positive biotin-avidin binding was observed with diaminobenzidine. All sections were visualized with a Leica microscope and measured using ImageJ software (NIH, Bethesda, Maryland). Approximately 125 fibers per muscle were analyzed.

\section{Total muscle protein determination}

Total muscle protein was determined from plantaris homogenates using previously described methods [49].
Briefly, frozen plantaris muscles were weighed, minced, and homogenized on ice using an electric tissue grinder in 40 volumes of buffer that contained: $50 \mathrm{mM}$ Tris, $\mathrm{pH}$ $7.5,150 \mathrm{mM} \mathrm{NaCl}, 0.1 \%$ SDS, $0.5 \%$ sodium deoxycholate, 1\% Nonidet P-40, 1 mM PMSF, and Complete, mini protease cocktail tablets from Roche (Indianapolis, IN). Protein concentrations were determined by using the Bio-Rad DC kit according to manufacturer's instructions. Total protein per plantaris muscle was expressed as the product of protein concentration and initial wet weight. Aliquots of these plantaris homogenates were processed for protein analyses via Western blot.

\section{Western blot analyses}

Equal amounts of protein were boiled for 2 minutes in sample buffer that contained: $0.5 \mathrm{M}$ Tris $-\mathrm{HCl}(\mathrm{pH} 6.8)$, $10 \%(\mathrm{v} / \mathrm{v})$ glycerol, $10 \%(\mathrm{w} / \mathrm{v})$ SDS, $5 \%(\mathrm{v} / \mathrm{v}) \beta$-mercaptoethanol, and $0.05 \%(w / v)$ bromophenol blue. Samples were separated by SDS-PAGE and transferred onto nitrocellulose membranes using a trans-blot SD semidry transfer cell (Biorad, Hercules, CA) according to manufacturer's instructions. All incubations were performed at room temperature unless otherwise noted. Membranes were blocked in 5\% BSA diluted in TTBS $(0.01 \%(\mathrm{w} / \mathrm{v})$ Tween-20) for $1 \mathrm{~h}$ and then incubated in primary antibodies against phospho-p38 and total p38 (each at 1:1000 in blocking buffer, Cell Signaling Technology, Beverly, MA) overnight at $4^{\circ} \mathrm{C}$. Blots were washed in TTBS, incubated in anti-rabbit-HRP IgG $(1 ; 2500$ in blocking buffer) for $1 \mathrm{~h}$, washed again and then developed with enhanced chemiluminescent plus western blotting detection system (GE Healthcare, Piscataway, NJ). Densitometry was performed using a Chemidoc XRS system and analyzed with Quantity One software (Biorad, Hercules, CA). Pathway activities are expressed as the ratios of phosphorylated protein to total protein.

\section{Gene expression analyses}

Plantaris muscles were collected, immediately frozen in liquid nitrogen, and stored at $-80^{\circ} \mathrm{C}$ until processed for real time PCR analyses as previously described $[15,16,27]$. Frozen plantaris muscles were thawed and homogenized in Trizol ( $1 \mathrm{ml} / 100 \mathrm{mg}$ tissue) using an electric tissue homogenizer. Total RNA $(2.5 \mu \mathrm{g})$ was reverse transcribed in a $40 \mu \mathrm{l}$ final reaction volume using random primers and M-MLV reverse transcriptase according to manufacturer's instructions (Invitrogen, Carlsbad, California).

Real time PCR products were analyzed using the iCycler iQ system (Bio-Rad, Hercules, California). cDNA (10 $\mu \mathrm{l}$ of a $1: 10$ dilution) was amplified in a $35 \mu \mathrm{l}$ reaction containing $400 \mathrm{~nm}$ gene-specific primer pair and iQ Sybr Green Supermix (Bio-Rad, Hercules, California). 
Primer sequences for LIF, CNTF, CT-1, IL-6, and TGF $\beta_{1}$ have been previously described $[15,16,27]$. Primer sequences for myostatin, activin IIB, and TNF $\alpha$ were as follows: myostatin, 5'-TAACCTTCCCAGGACCAGGA-3' and 5'-GCAATAATCCAGTCCCATCC-3'; activin IIB, 5'- CGACTTTGTGGCTGTGAAGA-3' and 5'-TCGTTCCACGTGTGATGATGTT-3'; TNF $\alpha$, 5'TGGCCCAGACCCTCACACTC-3' and 5'-CTCCTGG TATGAAATGGCAAATC-3'. Samples were incubated at $95^{\circ} \mathrm{C}$ for $15 \mathrm{~min}$, followed by 40 cycles of denaturation, annealing and extension at $95^{\circ} \mathrm{C}, 60^{\circ} \mathrm{C}$, and $72^{\circ} \mathrm{C}$, respectively. As a control, real time PCR was also performed on $2 \mu \mathrm{l}$ of each RNA sample to confirm absence of contaminating genomic DNA. All reactions were performed in triplicate and the starting quantities of the genes of interest were normalized to $18 \mathrm{~S}$ rRNA (primers supplied by Ambion, Austin, Texas). The $2^{-\Delta \Delta C}$ method was used to analyze alterations in gene expression and values were expressed as fold changes relative to control [15,16,27].

\section{Statistics}

One-way analyses of variance were performed followed by Student-Newman-Keuls post-hoc tests using SigmaStat v2.0 software. Significance was accepted at $\mathrm{p} \leq 0.05$.

\section{List of abbreviations}

CNTF: ciliary neurotrophic factor; CT-1: cardiotrophin-1; CSA: cross-sectional area; IGF-1: insulin-like growth factor-1; IL-6: interleukin-6; LIF: leukemia inhibitory factor; MHC: myosin heavy chain; MuRF: muscle ring finger protein; NIAAA: National Institutes of Alcohol Abuse and Alcoholism; SAIDS: terminal stage acquired immune deficiency syndrome in SIV-infected Rhesus macaques; SIV: simian immunodeficiency virus; TGF $\beta_{1}$ : transforming growth factor $\beta_{1}$

\section{Acknowledgements and Funding}

The authors are grateful for the excellent technical support of Todd Mills and Robert Raynor. This work was supported by grant K01 AA017190-02 from the National Institute on Alcohol Abuse and Alcoholism to JSO.

\section{Authors' contributions}

CC was responsible for real time PCR and histology. DG was responsible for tissue preparation, protein content analyses and data collection. MB was responsible for western blot analyses. JO was responsible for study design, research fund collection, figures and manuscript preparations. All authors have provided editorial content and have approved this final manuscript.

\section{Competing interests}

The authors declare that they have no competing interests.

Received: 16 March 2011 Accepted: 16 August 2011

Published: 16 August 2011

\section{References}

1. Kresina TF, Flexner CW, Sinclair J, Correia MA, Stapleton JT, Adeniyi-Jones S, Cargill V, Cheever LW: Alcohol use and HIV pharmacotherapy. AIDS Res Hum Retroviruses 2002, 18(11):757-770.

2. Moss M, Burnham EL: Chronic alcohol abuse, acute respiratory distress syndrome, and multiple organ dysfunction. Crit Care Med 2003, 31(4 Suppl):S207-212.

3. Reid W, Sadowska M, Denaro F, Rao S, Foulke J Jr, Hayes N, Jones O, Doodnauth D, Davis H, Sill A, et al: An HIV-1 transgenic rat that develops
HIV-related pathology and immunologic dysfunction. Proc Natl Acad Sci USA 2001, 98(16):9271-9276.

4. Franchi S, Sacerdote P, Moretti S, Gerra G, Leccese V, Tallone MV, Panerai $A E$, Somaini $L$ : The effects of alcoholism pharmacotherapy on immune responses in alcohol-dependent patients. Int J Immunopathol Pharmacol 23(3):847-855.

5. Naicker S, Fabian J: Risk factors for the development of chronic kidney disease with HIV/AIDS. Clin Nephrol 74(Suppl 1):S51-56.

6. Alcohol Alert. [http://pubs.niaaa.nih.gov/publications/aa57.htm].

7. Petry NM: Alcohol use in HIV patients: what we don't know may hurt us. Int J STD AIDS 1999, 10(9):561-570.

8. Fama R, Rosenbloom MJ, Nichols BN, Pfefferbaum A, Sullivan EV: Working and episodic memory in HIV infection, alcoholism, and their comorbidity: baseline and 1-year follow-up examinations. Alcohol Clin Exp Res 2009, 33(10):1815-1824.

9. Meyerhoff DJ: Effects of alcohol and HIV infection on the central nervous system. Alcohol Res Health 2001, 25(4):288-298.

10. Molina PE, Lang CH, McNurlan M, Bagby GJ, Nelson S: Chronic alcohol accentuates simian acquired immunodeficiency syndrome-associated wasting. Alcohol Clin Exp Res 2008, 32(1):138-147.

11. Lewis W: Cardiomyopathy in AIDS: a pathophysiological perspective. Prog Cardiovasc Dis 2000, 43(2):151-170.

12. Marcondes MC, Watry D, Zandonatti M, Flynn C, Taffe MA, Fox H: Chronic alcohol consumption generates a vulnerable immune environment during early SIV infection in rhesus macaques. Alcohol Clin Exp Res 2008, 32(9):1583-1592.

13. Cook RT: Alcohol abuse, alcoholism, and damage to the immune system-a review. Alcohol Clin Exp Res 1998, 22(9):1927-1942.

14. Rosenbloom MJ, Sullivan EV, Sassoon SA, O'Reilly A, Fama R, Kemper CA Deresinski S, Pfefferbaum A: Alcoholism, HIV infection, and their comorbidity: factors affecting self-rated health-related quality of life. $J$ Stud Alcohol Drugs 2007, 68(1):115-125.

15. Otis JS, Ashikhmin Yl, Brown LA, Guidot DM: Effect of HIV-1-related protein expression on cardiac and skeletal muscles from transgenic rats. AIDS Res Ther 2008, 5:8.

16. Otis JS, Guidot DM: Procysteine stimulates expression of key anabolic factors and reduces plantaris atrophy in alcohol-fed rats. Alcohol Clin Exp Res 2009, 33(8):1450-1459.

17. Pruznak AM, Hong-Brown L, Lantry R, She P, Frost RA, Vary TC, Lang CH: Skeletal and cardiac myopathy in HIV-1 transgenic rats. Am J Physiol Endocrinol Metab 2008, 295(4):E964-973.

18. Lang CH, Frost RA, Summer AD, Vary TC: Molecular mechanisms responsible for alcohol-induced myopathy in skeletal muscle and heart. Int J Biochem Cell Biol 2005, 37(10):2180-2195.

19. Preedy VR, Salisbury JR, Peters TJ: Alcoholic muscle disease: features and mechanisms. Journal of Pathology 1994, 173(4):309-315.

20. Molina PE, McNurlan M, Rathmacher J, Lang CH, Zambell KL, Purcell J, Bohm RP, Zhang P, Bagby GJ, Nelson S: Chronic alcohol accentuates nutritional, metabolic, and immune alterations during asymptomatic simian immunodeficiency virus infection. Alcohol Clin Exp Res 2006, 30(12):2065-2078.

21. Ray PE, Liu XH, Robinson LR, Reid W, Xu L, Owens JW, Jones OD, Denaro F, Davis HG, Bryant JL: A novel HIV-1 transgenic rat model of childhood HIV-1-associated nephropathy. Kidney Int 2003, 63(6):2242-2253.

22. Lassiter C, Fan $X$, Joshi PC, Jacob BA, Sutliff RL, Jones DP, Koval M, Guidot DM: HIV-1 transgene expression in rats causes oxidant stress and alveolar epithelial barrier dysfunction. AIDS Res Ther 2009, 6:1.

23. Yadav A, Pati S, Nyugen A, Barabitskaja O, Mondal P, Anderson M, Gallo RC, Huso DL, Reid W: HIV-1 transgenic rat CD4+ T cells develop decreased CD28 responsiveness and suboptimal Lck tyrosine dephosphorylation following activation. Virology 2006, 353(2):357-365.

24. Grody WW, Cheng L, Lewis W: Infection of the heart by the human immunodeficiency virus. Am J Cardiol 1990, 66(2):203-206.

25. Raidel SM, Haase C, Jansen NR, Russ RB, Sutliff RL, Velsor LW, Day BJ, Hoit BD, Samarel AM, Lewis W: Targeted myocardial transgenic expression of HIV Tat causes cardiomyopathy and mitochondrial damage. Am J Physiol Heart Circ Physiol 2002, 282(5):H1672-1678.

26. Yarasheski KE, Smith SR, Powderly WG: Reducing plasma HIV RNA improves muscle amino acid metabolism. Am J Physiol Endocrinol Metab 2005, 288(1):E278-284. 
27. Otis JS, Brown LA, Guidot DM: Oxidant-induced atrogin-1 and transforming growth factor-beta1 precede alcohol-related myopathy in rats. Muscle Nerve 2007, 36(6):842-848.

28. Nishikawa J, Sakuma K, Sorimachi Y, Yoshimoto K, Yasuhara M: Increase of Cardiotrophin-1 immunoreactivity in regenerating and overloaded but not denervated muscles of rats. Neuropathology 2005, 25(1):54-65.

29. Kami K, Morikawa Y, Sekimoto M, Senba E: Gene expression of receptors for IL-6, LIF, and CNTF in regenerating skeletal muscles. J Histochem Cytochem 2000, 48(9):1203-1213.

30. Spangenburg EE, Booth FW: Leukemia inhibitory factor restores the hypertrophic response to increased loading in the LIF(-/-) mouse. Cytokine 2006, 34(3-4):125-130.

31. Kim H, Jo C, Jang BG, Oh $U$, Jo SA: Oncostatin $M$ induces growth arrest of skeletal muscle cells in $\mathrm{G} 1$ phase by regulating cyclin D1 protein level. Cell Signal 2008, 20(1):120-129.

32. Fujita J, Tsujinaka T, Yano M, Ogawa J, Morita T, Taniguchi H, Shiozaki H, Monden M: [Participation of interleukin-6 to skeletal muscle proteolysis: the effect of IL- 6 administration on mRNA expression by the skeletal muscle cell proteolytic system]. Nippon Geka Gakkai Zasshi 1998, 99(5):332.

33. Li YP, Chen Y, John J, Moylan J, Jin B, Mann DL, Reid MB: TNF-alpha acts via p38 MAPK to stimulate expression of the ubiquitin ligase atrogin1/ MAFbx in skeletal muscle. FASEB J 2005, 19(3):362-370.

34. Durieux AC, Amirouche A, Banzet S, Koulmann N, Bonnefoy R, Pasdeloup M, Mouret C, Bigard X, Peinnequin A, Freyssenet D: Ectopic expression of myostatin induces atrophy of adult skeletal muscle by decreasing muscle gene expression. Endocrinology 2007, 148(7):3140-3147.

35. Trendelenburg AU, Meyer A, Rohner D, Boyle J, Hatakeyama S, Glass DJ: Myostatin reduces Akt/TORC1/p70S6K signaling, inhibiting myoblast differentiation and myotube size. Am J Physiol Cell Physiol 2009, 296(6): C1258-1270.

36. Lang CH, Frost RA, Svanberg E, Vary TC: IGF-I/IGFBP-3 ameliorates alterations in protein synthesis, elF4E availability, and myostatin in alcohol-fed rats. Am J Physiol Endocrinol Metab 2004, 286(6):E916-926.

37. Gilson H, Schakman O, Combaret L, Lause P, Grobet L, Attaix D, Ketelslegers JM, Thissen JP: Myostatin gene deletion prevents glucocorticoid-induced muscle atrophy. Endocrinology 2007, 148(1):452-460.

38. Amirouche A, Durieux AC, Banzet S, Koulmann N, Bonnefoy R, Mouret C Bigard $X$, Peinnequin A, Freyssenet D: Down-regulation of Akt/mammalian target of rapamycin signaling pathway in response to myostatin overexpression in skeletal muscle. Endocrinology 2009, 150(1):286-294.

39. Sartori R, Milan G, Patron M, Mammucari C, Blaauw B, Abraham R, Sandri M: Smad2 and 3 transcription factors control muscle mass in adulthood. Am J Physiol Cell Physiol 2009, 296(6):C1248-1257.

40. Gonzalez-Cadavid NF, Taylor WE, Yarasheski K, Sinha-Hikim I, Ma K, Ezzat S, Shen R, Lalani R, Asa S, Mamita M, et al: Organization of the human myostatin gene and expression in healthy men and HIV-infected men with muscle wasting. Proc Natl Acad Sci USA 1998, 95(25):14938-14943.

41. Spangenburg EE, Brown DA, Johnson MS, Moore RL: Exercise increases SOCS-3 expression in rat skeletal muscle: potential relationship to IL-6 expression. Journal of Physiology 2006, 572(Pt 3):839-848.

42. Spangenburg EE, Booth FW: Multiple signaling pathways mediate LIFinduced skeletal muscle satellite cell proliferation. American Journal of Physiology - Cell Physiology 2002, 283(1):C204-211.

43. Lang CH, Wu D, Frost RA, Jefferson LS, Kimball SR, Vary TC: Inhibition of muscle protein synthesis by alcohol is associated with modulation of elF2B and elF4E. Am J Physiol 1999, 277(2 Pt 1):E268-276.

44. Preedy VR, Peters TJ: The effect of chronic ethanol ingestion on protein metabolism in type-l- and type-Il-fibre-rich skeletal muscles of the rat. Biochemical Journal 1988, 254(3):631-639.

45. Zhang $P$, Chen $X$, Fan M: Signaling mechanisms involved in disuse muscle atrophy. Med Hypotheses 2007, 69(2):310-321.

46. Fernandez-Sola J, Preedy VR, Lang CH, Gonzalez-Reimers E, Arno M, Lin JC, Wiseman H, Zhou S, Emery PW, Nakahara T, et al: Molecular and cellular events in alcohol-induced muscle disease. Alcohol Clin Exp Res 2007, 31(12):1953-1962.

47. Vary TC, Frost RA, Lang CH: Acute alcohol intoxication increases atrogin-1 and MuRF1 mRNA without increasing proteolysis in skeletal muscle. Am J Physiol Regul Integr Comp Physiol 2008, 294(6):R1777-1789.
48. Chen LH, Huang CY, Osio Y, Fitzpatrick EA, Cohen DA: Effects of chronic alcohol feeding and murine AIDS virus infection on liver antioxidant defense systems in mice. Alcohol Clin Exp Res 1993, 17(5):1022-1028.

49. Chakravarthy MV, Davis BS, Booth FW: IGF-I restores satellite cell proliferative potential in immobilized old skeletal muscle. Journal of Applied Physiology 2000, 89(4):1365-1379.

doi:10.1186/1742-6405-8-30

Cite this article as: Clary et al:: Chronic alcohol ingestion exacerbates skeletal muscle myopathy in HIV-1 transgenic rats. AIDS Research and Therapy 2011 8:30.

\section{Submit your next manuscript to BioMed Central and take full advantage of:}

- Convenient online submission

- Thorough peer review

- No space constraints or color figure charges

- Immediate publication on acceptance

- Inclusion in PubMed, CAS, Scopus and Google Scholar

- Research which is freely available for redistribution

Submit your manuscript at www.biomedcentral.com/submit
C) Biomed Central 